\title{
ENVIRO-HIRLAM: on-line coupled modelling of urban meteorology and air pollution
}

\author{
A. Baklanov, U. Korsholm, A. Mahura, C. Petersen, and A. Gross \\ Danish Meteorological Institute, DMI, Lyngbyvej 100, 2100 Copenhagen, Denmark \\ Received: 28 December 2007 - Revised: 21 April 2008 - Accepted: 22 April 2008 - Published: 7 May 2008
}

\begin{abstract}
The strategy of new generation integrated Meso-Meteorological (MetM) and Atmospheric Chemical Transport (ACT) models for predicting atmospheric composition, meteorology and climate change is discussed for the Enviro-HIRLAM (HIgh Resolution Limited Area Model) integrated system. Current progress in the Enviro-HIRLAM system development and its urban on-line coupled modelling applications is considered. Results of several sensitivity studies of the urban effects (urban albedo and roughness, anthropogenic heat flux, heat island, and urban aerosols) on meteorology and air pollution at different scales are presented. Several sensitivity tests of the off-line versus on-line coupling of MetM and ACT models in Enviro-HIRLAM as well as their verification versus the ETEX experiment are considered and results are discussed.
\end{abstract}

\section{Introduction}

The strategy of new generation integrated MesoMeteorological (MetM) and Atmospheric Chemical Transport Model (ACTM) systems suggest considering the urban air quality as a combination and integration, at least, of the following factors: air pollution, meteorological/ climatic conditions, and population exposure. These are reasonable to consider altogether due to facts that: (i) meteorology is a main source of uncertainty in air pollution and emergency preparedness modelling, (ii) complex and combined effects of meteorological and pollution components on human health (e.g., hot spots in July of 2003 in Paris, France), (iii) effects of pollutants, especially aerosols, on climate forcing and meteorological phenomena (precipitation, thunderstorms, etc.). In this context several levels of the integration strategy are considered:

1. off-line models:

- separate ACTMs are driven by meteorological input data from meteo-pre-processors, measurements or diagnostic models,

- separate ACTMs are driven by analysed or forecasted meteodata from Numerical Weather Prediction (NWP) archives/ datasets,
- separate ACTMs read output-files from operational NWP models or specific MetMs with a limited period of time (e.g. 1, 3, 6h);

2. on-line models:

- on-line access models, when meteodata is available at each time step (it could be via a model interface as well),

- on-line integration of ACTM into MetM, when feedbacks are possible to consider (we will use this definition as on-line coupled modelling).

The on-line integration of MetM and ACTM models (Fig. 1) gives a possibility to utilise in ACTM all meteorological 3-D fields at each time step and to consider feedbacks of air pollution (e.g. urban aerosols) on meteorological processes and climate forcing. This is very promising way for future atmospheric simulation systems leading to a new generation of models for environmental and "chemical weather" forecasting. In particular, this way is considered in the COST Action 728 (http://www.cost728.org) and realised by several partner teams, and in particular, by the DMI team in the frameworks of the Enviro-HIRLAM system developments (Chenevez et al., 2004; Baklanov et al., 2004; Korsholm et al., 2008) as a continuation of the FUMAPEX project (http://fumapex.dmi.dk; EMS-FUMAPEX, 2005). 


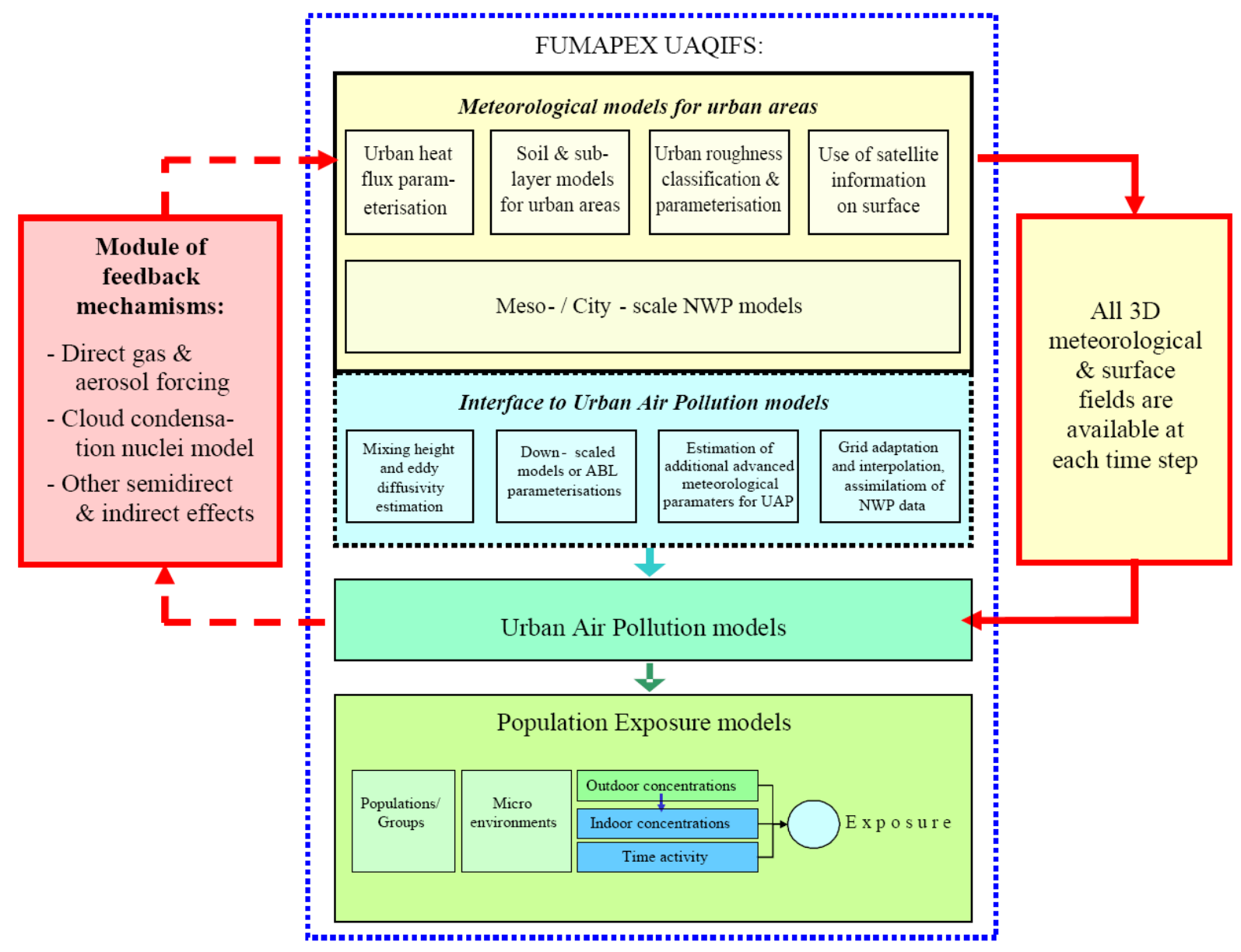

Figure 1. On-line integrated system structure: Extended FUMAPEX scheme of the improvements of meteorological forecasts (NWP) in urban areas, interfaces and on-line integration with Urban Air Pollution and population exposure models for urban air quality information forecasting and information systems (UAQIFS).

\section{ENVIRO-HIRLAM on-line coupled modelling system}

\subsection{On-line integration strategy}

The Enviro-HIRLAM is developing as a fully on-line (with a possibility of the off-line coupling as well) integrated system based on the DMI-HIRLAM NWP model with ACTM implemented in the model (Fig. 1). The system realisation includes the following steps:

1. nesting of models for higher resolutions,

2. improved resolving of boundary and surface layers characteristics and structures,

3. different levels of urbanisation,

4. improvement of advection schemes,

5. implementation of chemical mechanisms,

6. implementation of aerosol dynamics,
7. realisation of feedback mechanisms,

8. assimilation of monitoring data.

The Enviro-HIRLAM modelling system includes on-line coupled tracers, based on Chenevez et al. (2004) and it has implemented a versatile aerosol-cloud module and heterogeneous chemistry in their ACTM (Gross and Baklanov, 2004). Implementation of the ACTM in the Enviro-HIRLAM makes possible an inclusion of feedbacks (regional to urban scale) between the ACTM and NWP models (see the red box and dashed arrows in Fig. 1) (Baklanov et al., 2004; Baklanov and Korsholm, 2008).

\subsection{Model urbanisation}

Following the FUMAPEX project strategy to improve NWP and MetM models the urbanisation includes the following aspects and processes (Baklanov et al., 2005):

1. Model down-scaling, including increasing vertical and horizontal resolution and nesting techniques; 

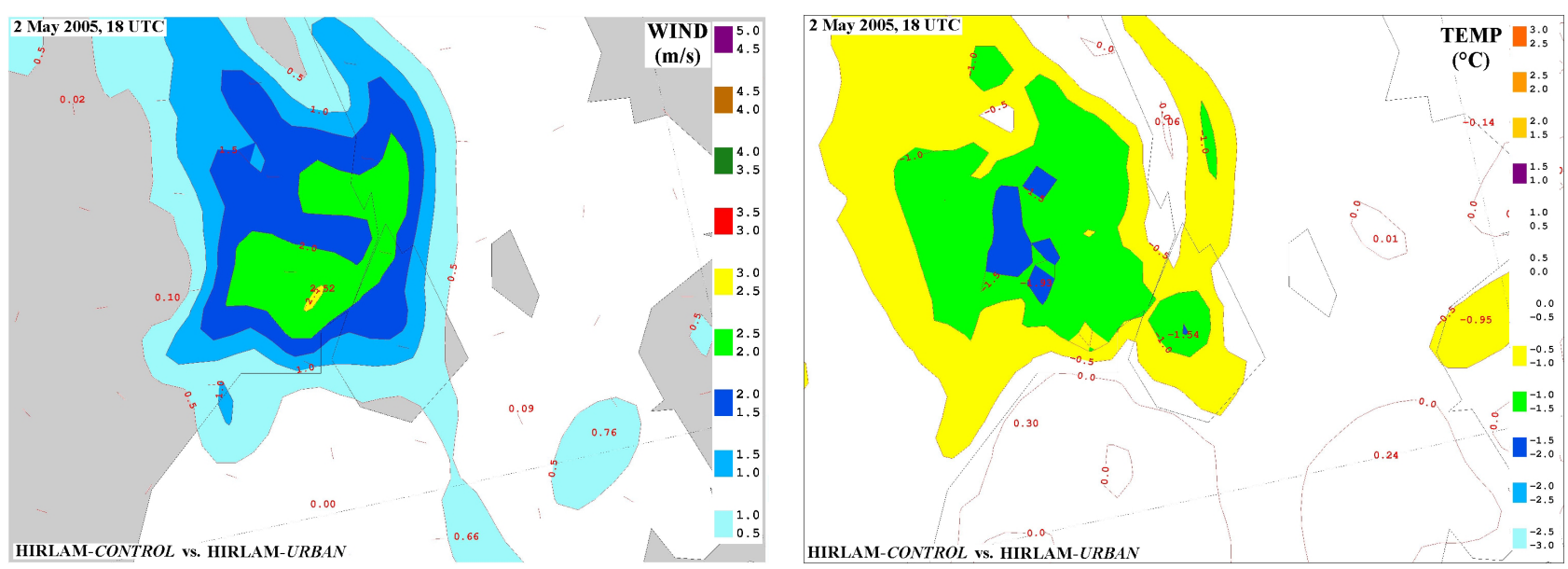

Figure 2. Plots of difference fields (between outputs of the HIRLAM control vs. HIRLAM urban runs) for the (a) wind velocity at $10 \mathrm{~m}$ and (b) air temperature at $2 \mathrm{~m}$ for forecasts at 18:00 UTC on 2 May 2005 for the Copenhagen metropolitan area.

2. Modified high-resolution urban land-use classifications, parameterizations and algorithms for roughness parameters in urban areas based on the morphologic method;

3. Specific parameterization of the urban fluxes in the meso-scale model;

4. Modelling/parameterization of meteorological fields in the urban sublayer;

5. Calculation of the urban mixing height based on prognostic approaches.

Several options for the integrated FUMAPEX urban module usable with the HIRLAM NWP model have been considered (Baklanov et al., 2008). The first module (which considers modifications of the roughness, anthropogenic heat flux, and albedo) is the cheapest way of "urbanising" the model and it can be easily implemented into operational NWP models (Mahura et al., 2005a; Baklanov et al., 2005) as well as in Regional Climate Models. The second - Building Effect Parameterization (BEP) (Martilli et al., 2002) - module gives a possibility to consider the energy budget components and fluxes inside the urban canopy although it is a relatively more expensive $(\approx 5-10 \%$ computational time increase) (Mahura et al., 2008). However, this approach is sensitive to the vertical resolution of NWP models and is not very effective if the first model level is higher than $30 \mathrm{~m}$. Therefore, the increasing of the vertical resolution of current NWP models is required. The third - Soil Model for SubMeso Urbanized (SM2-U) version (Dupont and Mestayer, 2006; Dupont et al., 2006) - module is considerably more expensive computationally than the first two modules (Mahura et al., 2005b). However, the third one provides the possibility to accurately study the urban soil and canopy energy exchange including the water budget. Therefore, the second and third modules are recommended for use in advanced urban-scale NWP and meso-meteorological research models.

\section{Examples}

\subsection{Results of NWP model urbanization}

Diurnal variability of meteorological variables - temperature at $2 \mathrm{~m}$ and wind velocity at $10 \mathrm{~m}$ - for the urbanized HIgh Resolution Limited Area Model (HIRLAM) with BEP module is evaluated for the Copenhagen metropolitan area and surroundings. The difference fields between (control minus urbanized) runs, as an example, are shown in Fig. 2 for the 2 May 2005 with dominating low velocity winds. The specific case studies with different meteorological conditions (low, typical, and high winds) for the model runs (with a horizontal resolution of $1.4 \mathrm{~km}$ ), and considering impact on the metropolitan area. It was found that urbanization of the HIRLAM model can modify the wind velocity by up to $2.5 \mathrm{~m} / \mathrm{s}$. For the temperature, the urbanized version always showed the higher values by up to $1.8^{\circ} \mathrm{C}$. In general, during 09:00-15:00 UTCs the latent heat flux difference is negligible - less than $1 \mathrm{~W} / \mathrm{m}^{2}$, although it can be up to $20 \mathrm{~W} / \mathrm{m}^{2}$ during the late evening and night hours. It can be summarized that in specific meteorological situations, especially during the low wind conditions, the urban effects may be of considerable importance over the large metropolitan areas. The high-resolution simulations with urbanization provide the possibility to incorporate the urban effects into NWP modelling.

\subsection{Results of on-line modelling}

The current version of Enviro-HIRLAM is able to run in off-line mode facilitating comparison between off-line and 

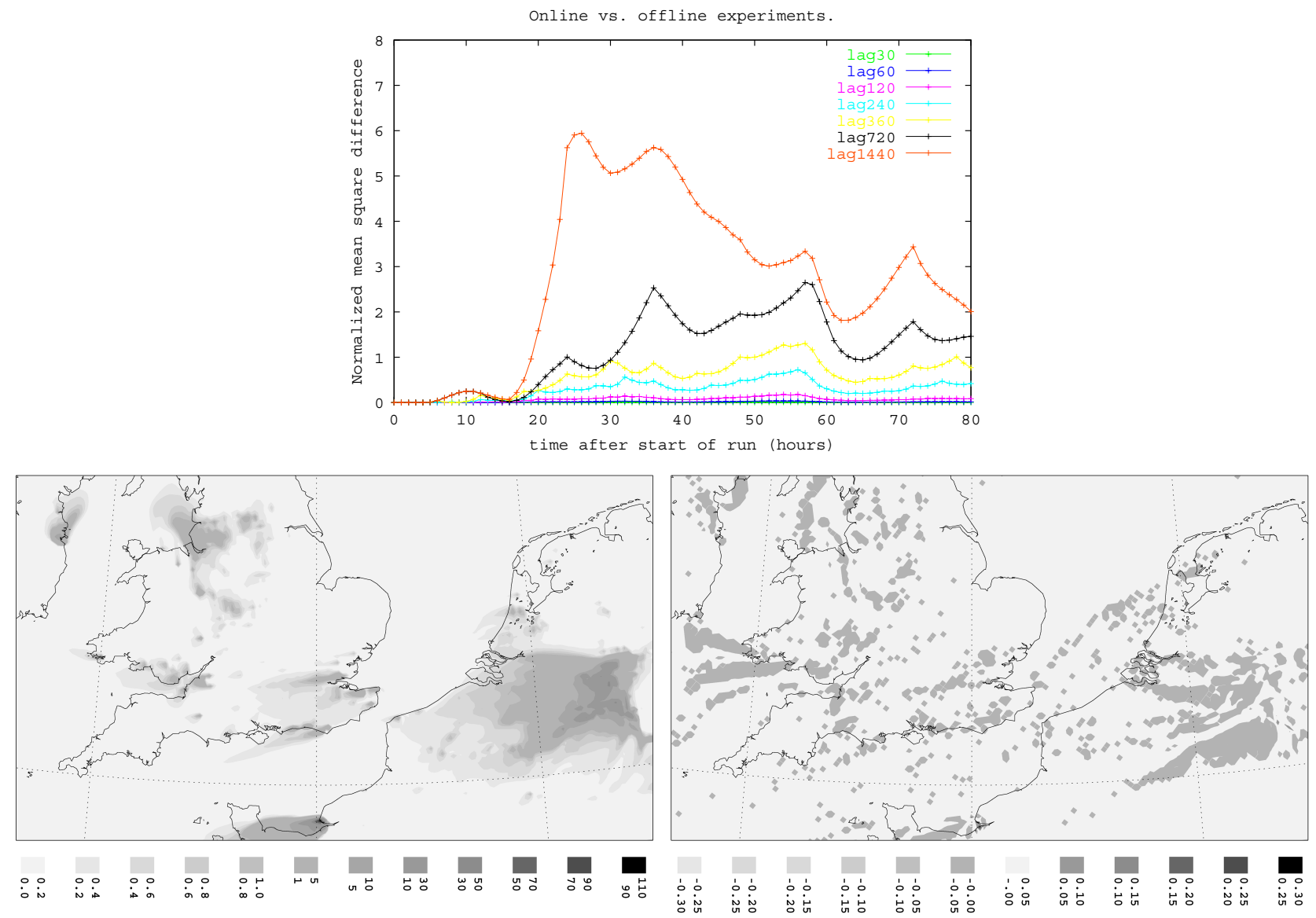

Figure 3. (a) Normalized mean square error versus time at ETEX station (DK02) for the on-line and off-line simulations. The simulation was initialised four hours before the start of the release. (b) Reference run and difference (reference - perturbation) in accumulated dry deposition $\left(\mu \mathrm{g} / \mathrm{m}^{2}\right)$, after $36 \mathrm{~h}$ of simulation time, over the Ruhr area.

on-line runs. During off-line runs advection was updated with relevant meteorological fields every $0.5,1,2,4,6,12$ and $24 \mathrm{~h}$ (using constant input in between updates). Simulations of the ETEX-1 (Nodop, 1998) release were conducted and comparison with observations was used to calculate statistical quantities at specific stations. As the off-line coupling interval increase, so does the error, which becomes of considerable size when the coupling interval is between two and four hours (Fig. 3a).

Another example of usage considers the effect of adding feedbacks between aerosols and meteorology by including the first indirect effect (Twomey, 1977). EMEP PM $_{2.5}$ emissions from urban areas were considered in a situation with low cloud cover and low wind speed over northern Europe. A perturbed run including feedbacks was compared to a reference run. Changes in accumulated dry deposition occurred over the major polluted areas if low cloud cover was present (Fig. 3b). After $36 \mathrm{~h}$ changes of up to $2 \%$ (corresponding to $260 \mu \mathrm{g} / \mathrm{m}^{2}$ ) was found over Northern France. Dry deposition is directly related to atmospheric stability. As aerosols are mixed into cloud environments the cloud albedo and thereby columnar temperature profiles below the clouds are modified and this may give rise to changes in stability.

The simulation results show that the effects of urban aerosols on the urban boundary layer height, $h$, could be of the same order of magnitude as the effects of the urban heat island ( $\Delta h \approx 100-200 \mathrm{~m}$ for the nocturnal boundary layer). This confirms the importance of on-line integrated modelling of urban meteorology together with air pollution and considering the urban aerosol feedback mechanisms.

\section{Conclusions}

Different parameterisations of the urban sublayer have been analysed, tested with urban-scale versions of the HIRLAM NWP model. It was shown that the implementation of the urban modules can improve the forecasted meteorological and 
air pollution fields for urban areas although does not significantly increase the overall performance of the NWP model.

Our preliminary tests of the off-line vs. on-line integrations of Enviro-HIRLAM showed that the on-line integration of MetMs and ACTMs with consideration of the feedbacks of air pollution (e.g. urban aerosols) on meteorological processes and urban climate is a promising way for development of future systems of atmospheric environment forecasting.

Main advantages of the on-line and off-line modelling approaches from the first preliminary outlook are the following:

For the on-line coupling:

- Only one grid; no interpolation in space;

- No time interpolation;

- Physical parameterizations and numerical schemes are the same; no inconsistencies;

- All 3-D meteorological variables are available at each time step; no restriction in variability of meteorological fields;

- Possibility to consider feedback mechanisms;

- No need of meteo- pre/post-processors.

For the off-line coupling:

- Possibility of independent parameterizations;

- Low computational cost for poor-resolution runs (if NWP data - available, no need to run MetM);

- More suitable for ensembles and operational activities;

- Easier to use for the inverse modelling and adjoint problem;

- Independence of atmospheric pollution model runs on MetM computations;

- More flexible grid construction and generation for ACTMs,

- Suitable for emission scenarios analysis and air quality management.

Edited by: S. Joffre

Reviewed by: two anonymous referees

\section{References}

Baklanov, A.: Meteorological advances and systems for urban air quality forecasting and assessments. Short Papers of the 5th International Conference on Urban Air Quality Valencia, Spain, 29-31 March 2005, CLEAR, 22-25, 2005.

Baklanov, A., Gross, A., and Sørensen, J. H.: Modelling and forecasting of regional and urban air quality and microclimate, J. Computational Technologies, 9, 82-97, 2004.

Baklanov, A., Mahura, A., Nielsen, N. W., and Petersen, C.: Approaches for urbanization of DMI-HIRLAM NWP model, HIRLAM Newsletter, 49, 61-75, 2005.

Baklanov, A. and Korsholm, U.: On-line integrated meteorological and chemical transport modelling: advantages and prospective. In: Preprints ITM 2007: 29th NATO/SPS International Technical Meeting on Air Pollution, Modelling and its Application, 2428.09.2007, University of Aveiro, Portugal, 21-34, 2007.

Baklanov, A., Mestayer, P., Clappier, A., Zilitinkevich, S., Joffre, S., Mahura, A., and Nielsen, N. W.: Towards improving the simulation of meteorological fields in urban areas through updated/advanced surface fluxes description, Atmos. Chem. Phys., 8, 523-543, 2008, http://www.atmos-chem-phys.net/8/523/2008/.

Chenevez, J., Baklanov, A., and Sørensen, J. H.: Pollutant transport schemes integrated in a numerical weather prediction model: Model description and verification results, Meteorol. Appl., 11(3), 265-275, 2004.

Dupont, S., Mestayer, P., Guilloteau, E., Berthier, E., and Andrieu H.: Parameterization of the Urban Water Budget with the Submesoscale Soil Model, J. Appl. Meteorol. Clim., 45(4), 624-648, 2006.

Dupont, S. and Mestayer, P.: Parameterization of the Urban Energy Budget with the Submesoscale Soil Model, J. Appl. Meteorol. Clim., 45(12), 1744-1765, 2006.

EMS-FUMAPEX: Urban Meteorology and Atmospheric Pollution, edited by: Baklanov, A., Joffre, S., and Galmarini, S., Atmos. Chem. Phys., Special Issue, 2005.

Gross, A. and Baklanov, A.: Modelling the influence of dimethyl sulphide on the aerosol production in the marine boundary layer, Int. J. Environ. Pollut., 22, 51-71, 2004.

Korsholm, U., Baklanov, A., Mahura, A., Petersen, C., Lindberg, K., Gross, A., Rasmussen, A., Sørensen, J. H., and Chenevez, J.: ENVIRO-HIRLAM. An On-Line Coupled MultiPurpose Environment Model, ACCENT/GLOREAM Workshop 2006 Proceedings, available at: http://euler.lmd.polytechnique. fr/gloream/, 2006.

Korsholm, U., Baklanov, A., Gross, A., and Sørensen, J. H.: On the importance of the meteorological coupling interval in air pollution modeling, Atmos. Environ., submitted, 2008.

Mahura, A., Baklanov, A., Petersen, C., Sattler, K., Amstrup, B., and Nielsen, N. W.: ISBA Scheme Performance in High Resolution Modelling for Low Winds Conditions, HIRLAM Newsletter, 49, 22-35, 2005a.

Mahura, A., Leroyer, S., Mestayer, P., Calmet, I., Dupont, S., Long, N., Baklanov, A., Petersen, C., Sattler, K., and Nielsen, N. W.: Large eddy simulation of urban features for Copenhagen metropolitan area, Atmos. Chem. Phys. Discuss., 5, $11183-$ $11213,2005 b$.

Mahura, A., Petersen, C., Baklanov, A., Amstrup, B., Korsholm, U. S., and Sattler, K.: Verification of long-term DMI-HIRLAM 
NWP model runs using urbanization and building effect parameterization modules, HIRLAM Newsletter, 53, 50-60, 2008.

Martilli, A., Clappier, A., and Rotach, M. W.: An Urban Surface Exchange Parameterisation for Mesoscale Models, Bound.-Lay. Meteorol., 104, 261-304, 2002.
Nodop, K., Connolly, R., and Girardi, F.: The Field Campaigns of the European Tracer Experiment (ETEX): Overview and results, Atmos. Environ., 32(24), 4095-4108, 1998.

Twomey, S. A.: The influence of pollution on the short wave albedo of clouds, J. Atmos. Sci., 34, 1149-1152, 1977. 